\title{
Globalization and export flows between Eurasian Economic Union countries: a gravity model approach
}

\author{
Juliet Abakumova ${ }^{1}$, Olena Primierova ${ }^{2, *}$ \\ ${ }^{1}$ Department of Analytical Economics and Econometrics, Belarusian state university, Minsk, Belarus \\ ${ }^{2}$ Department of Finance, National university of Kyiv-Mohyla academy, Kyiv, Ukraine
}

\begin{abstract}
In the empirical tools for the research of trade integration a special place is occupied by gravity models, insofar as these models have rather high accuracy in explaining mutual trade flows. Recently, however, the gravity model approach has been subjected to critical rethinking: globalization brought considerable changes not only in economic growth, but also in international trade, what allowed speaking about a "Death of Distance". At the same time, estimates based on gravity models almost always demonstrated an increase in the coefficient of distance as a proxy for transport costs, which contradicts the general perception of the phenomenon of globalization. The paper is devoted to testing the validity of inclusion of the globalization index in the model, which would allow consider the role of globalization in bilateral cross-country trade, as well as testing the hypothesis of reducing the coefficient of distance. Based on the annual panel data over the period 2000-2016 the trade integration model for the EEU countries was estimated. To test the hypothesis of a decrease in the estimated coefficient of distance over time, the gravity model was also evaluated at different time intervals. And the positive impact of the globalization factor on the volume of exports is revealed.
\end{abstract}

\section{Introduction}

Within the framework of the world economy, under the influence of globalization, the national economies of individual countries are becoming more open and oriented towards international economic cooperation. In modern conditions, practically no country in the world can effectively develop without interacting with other states. Countries are united based on their political, economic, geopolitical or geo-economic interests. Integration processes in the world are rapidly gaining momentum. To realize these interests, various integration groups are created. There are about 300 multilateral economic integration associations in the world (we are talking about various regional trade agreements establishing a degree and format of economic integration - free trade zones, customs unions, other forms of integration). International economic integration is regarded by many as a source of stabilization and development of the national economy. To one of the forms

\footnotetext{
*Corresponding author: o.primierova@ukma.edu.ua
} 
of economic integration can be attributed to trade integration, when, in order to obtain benefits from international specialization, special conditions of trade are established between several countries.

The scientific base, which is a totality (portfolio) of models and methods for analyzing bilateral international economic relations of the country, allowing to evaluate the effectiveness, potential and features of the development of cooperation with a partner country, is a necessary minimum for continuous monitoring of the state of international cooperation and creating directions for improving bilateral relations. In the empirical tools of research on trade integration, a special place is occupied by gravity models. The classical gravitational model is based on the Newton's law of gravitation: trade flows or trade integration (estimated, as a rule, by export or import) between the two countries depend on the scale of their economies (for example, from GDP) and the distance between them (centers of business activity or capitals). For the first time, this approach, describing bilateral aggregate trade flows between two countries A and B by analogy with the universal law of gravitation can be found at Jan Tinbergen [1].

Currently, applied research uses various versions of the gravity model, in which the exogenous variables may include indicators of population, country area, border length, as well as dummy variables that are responsible for socio-cultural, climatic and other differences. Gravity models have rather high accuracy in explaining mutual trade flows, i.e. forecasts and estimates of the potential trade relations obtained using gravity models have good statistical characteristics. High explanatory ability and relative simplicity of use, as well as the ability to include additional explanatory factors, besides to standard ones, contribute to the successful use of such models in practice [2]. In general terms, the equation of the gravity model can be represented as follows:

$$
E_{i j, t}=F\left(Z_{i, t} ; Z_{j, t} ; R_{i j, t}\right)
$$

где $E_{i j, t}$ - export from country $i$ to $j ; Z_{i, t}$ - domestic factors of the country $i$, determining export supply; $Z_{j, t}$ - domestic factors of the country $j$, determining import demand; $R_{i j, t}-$ intensity factor of trade flow from country $i$ to country $j$, determined by the geographic location of countries and transport features (type of transportation, distance between countries etc.).

The sample may consist not only of countries, but of firms, enterprises or firm-country pairs. Case Study of firm-country pairs based sample between 1995 and 2005, where distance is considered as distance between home and foreign markets, also confirms a negative impact on the probability that firm exports to that destination, as well as negative impact on export revenues for a firm [3].

The empirical results obtained using gravity models are convincing: for different types of data, different countries, different specifications of models and the econometric methods used, the role of the distance and size (scale) of economies is confirmed. So, Disdier and Head analyzed 1467 distance coefficient estimates in the equations of the gravity model for international trade, presented in 103 articles [4]. If don't take into account the variance of the estimates, most of the estimates (about 90\%) are in the interval between $-1,55$ и $-0,28$, i.e. values fluctuate relative to -1 . At the same time, it is noted that the values of the distance coefficient remain quite stable over a long period, only slightly increasing from 1950. The elasticity factors for the size of the economy, measured in terms of gross domestic product, are also stable and take values close to unity. In publications on evaluations of trading models in which distance is considered as a proxy for transport costs, i.e. measure of trade barriers, one can find various estimates for interval boundaries of variation of the corresponding distance coefficient. For instance, interval width may be narrower - [-1.3;-0.8] [5]. In general, different values of the distance coefficient in the 
gravity model can be determined by the general specification of the model, or by the characteristics of the additional variables included in the regression, but in any case, it is noteworthy that the fluctuations observed relative to a value close to -1 are common to them. Even if it comes not talking about traditional logarithmic regression, but about Poisson regression, in which elasticity estimates are more correct, their values are also stable during the period, but take smaller values (0.6-0.7 in absolute terms) [6]. Considering the specifics of the sample under consideration, publications devoted to the modeling of bilateral trade relations for EEU and CIS countries were analyzed for comparison (as a rule, assessments of integration potential are considered both within the framework of these communities and with other associations, for example, the EU), in which examples of distance elasticity estimates close to unity were also found [7, 8].

The fact that the distance elasticity of trade has remained stable around -1 for such a long time and in such different countries has been questionable and difficult to explain. In all considered models, given that trade costs increase with distance logarithmically, the distance elasticity of trade is the product of some internal parameters of the model with the distance elasticity of trade barriers. In order to explain why the distance coefficient is close to -1 , one needs to somehow align these model parameters. Even if such an alignment was to happen in a particular year, for a particular sector and a specific country, it is difficult to understand how it can retain its effect for so long. Over the past period, a lot has undergone significant changes: the nature of goods sold, transportation technologies, various barriers and obstacles to trade, the geopolitical and economic situation of countries trading in these goods. In other words, all parameters defined by various existing trading theories have evolved over time, while the empirical distance coefficient in the gravity equation remains almost constant.

Talking about the changes that have occurred and are taking place in international trade, and which should have somehow reflected on the parameters of gravity models, in particular, on the value of distance elasticity, it is necessary to mention "Distance Puzzle". It is believed that ceteris paribus globalization should generate dispersion of economic activity, reflecting decline of the transaction costs, especially in the case of transportation costs. All this should have led with time to the so-called "Death of distance". On the other hand, empirical studies based on the traditional gravity model of international trade most often do not lead to this conclusion. Moreover, if the model is evaluated independently over several years, the absolute value of the distance coefficient almost always increases with time [9]. This contradicts the general perception of globalization, i.e. the assumption that distance should become less important over time in international trade, which means a decrease, not an increase, in the estimated distance coefficient (its absolute value).

When discussing such paradoxical results, one is usually referred primarily to the study of Brun and others based on the traditional gravity model [10]. Although before that it was already noted that the effect of distance on the structure of trade does not decrease with time, contrary to popular belief, the world is not getting much smaller [11, 12]. Having analyzed literature on international trade and the effects of distance, the authors came to the logical conclusion that "dispersion of economic mass is the answer, not a shrinking globe". Thus, estimates of the influence of distance in empirical gravity regressions are not able to capture the consequences of globalization and remain constant in time, which is called "Distance Puzzle" in international trade or "Missing Globalization Puzzle". Puzzle is defined as the inability to reduce trade-related costs, which will be reflected in the estimates of the standard gravity model of bilateral trade [13]. The authors of the term considered various explanations of the paradox in the literature. One of them is the exclusion of zero observations from the model, which may affect the estimation of the influence of distance in time due to changes in the structure of trade. Another is that the traditional gravity model 
omits what is currently called "multilateral trade resistance". As a third explanation, the possibility of incorrect specification of the function of transport costs due to the missed variable bias can be given. Well, for example, in some publications there is an interpretation that changing distance costs are largely reflected in the constant term [14]. In this case, even the estimated reduction in distance costs will be consistent with the fact that the distance coefficient does not change with time.

Many authors made a definite contribution to the study of the paradox, empirically checking the stability of the puzzle and the possibility of its solution. Some result was obtained using several versions of the specification of the gravity model based on data for 130 countries for 1962-1996 [5]. The puzzle showed its stability in most variants, but certain results in the direction of a significant reduction were obtained for specification which to include remoteness (or an index of multilateral trade resistance). Adding an augmented trade barrier function (real price of oil, index of infrastructure, and share of primary exports in total bilateral trade) yielded plausible estimates of the expected death of distance. Shown, that the introduction of an "augmented" barrier-to-trade function removes the paradox for trading function eliminates the mentioned paradox, leading to a decrease in the estimate of trade elasticity by a distance of about 11 percent over a 35 -year period for the entire sample. It is noted that «Death of Distance» to a large extent limited to cases of bilateral trade between rich countries.

The fact that distance plays a significant role in trade integration in global markets for low income (or poor) countries, quite often found as conclusions from empirical studies. This is also emphasized by Borchert and Yotov, with the general conclusion that, on average, the effect of distance has decreased, while the effect of proximity and regional trade agreements has increased over time [15]. To confirm their conclusions, the authors used a sample of 69 countries in the period 1986-2006. This may indicate a positive impact of globalization processes, because it is explained by factors that can be associated with this phenomenon (diffusion of new technologies, production fragmentation etc.). It is logical to assume that estimates of the impact of distance on trade vary at the level of a particular country, since the consequences of globalization are uneven (obviously in favor of countries with average incomes and above). It has previously been suggested that in order to solve the "Distance Puzzle" it would suffice to evaluate the effect of distance on international trade with respect to the effect of distance on domestic trade [16]. The influence of distance on trade in gravitational with time should steadily decrease, insofar as gravity model is well suited to capture globalization effects.

A definite justification for the role of distance in the gravity model is given by Chaney [17]. It is argued that even if technological, political, economic changes affect a particular form of the firm level exports, in total, the gravity equation remains virtually unchanged. A certain emphasis is placed on explaining why the value of the coefficient of elasticity of foreign trade at a distance fluctuates around - 1 . The impact of distance on aggregate trade therefore depends on the form of the distribution of firm sizes. If firm sizes are well approximated by Zipf's law, then the distance elasticity of trade ought to be close to -1 . Received result holds irrespectively of the true impact of geographic distance on firm level trade. As long as company representatives communicate directly with their customers and suppliers, and as long as the information penetrates these direct interactions, we should expect that aggregate trade is close to the proportional size of the country and inversely proportional to the distance. Chaney also believes that the effect of distance on trade does not have to change with changes associated with the types of goods, technologies for trading these goods, changes in political barriers to trade, sets of countries involved in trade, etc. 
Thus, an attempt to solve the paradox leads researchers to different conclusions. Indeed, not all authors agree that a some paradox exists. Some initially casting doubt on the idea that distance elasticity in gravity model must somehow respond to globalization processes. So, though a general decrease in transport tariffs motivate international trade in comparison with domestic one, it does not mean that uniform decrease in transport costs might lead to increased international trade. Similarly, it does not imply a necessarily decreasing elasticity of trade to distance [18]. Others take the position that the reason lies in the fact that it is necessary to change the methods used and introduce new variables that will better capture the ongoing changes and relationships in the new conditions [19]. In any case, it all comes down to the fact that it's too early to declare the death of distance.

\section{Methods}

Based on the available publications for the countries of the sample, it was decided to take the traditional gravity model as a basis and test the hypothesis of a decreasing the role of distance within the framework of EEU. The latter can be considered as a result of integration processes, and integration, in turn, can be considered as a tool and a special case of globalization. As a variable that can increase the power of model response to globalization processes, the introduction of a globalization index KOF was provided.

Gravity models can be estimated based on both cross-sectional and panel data. In the first case, quite often models are built for different time periods, but based on the same cross-sectional sample, which allows assessing changes in trade flows, the effectiveness of integration processes, etc. In most modern empirical studies applying gravity models panel data is used. If talk about "Distance Puzzle", then exactly consideration year-by-year regressions, according to many authors, leads to the estimation of the distance coefficient does not reflect the real effect of the distance на bilateral trade [20]. On the other hand, this is also an easy way to track changes in the estimation of elasticity of trade to distance, even using panel data - changing the time interval. Using panel data allows you to take into account the relationship between variables in time, as well as individual effects between trading partners. If one talk about individual (fixed) effects, then when assessing the traditional gravity model, it may be difficult to evaluate them when using the distance between capitals as a measure of the distance between countries. In the case of the EEU countries, it is the capitals that have been the centers of business activity for a long time. In this case, considering a model with fixed individual effects is problematic, because leads to a singular matrix, a pooled regression or model with random effects is used if the validity, consistency and effectiveness of the corresponding estimates is confirmed.

For an empirical study of regional trade of the countries of the Eurasian Economic Union, data on bilateral trade in the period 2000-2016 were used. As variables of export and GDP of the participating states, the data presented in the databases of national statistical services, the Eurasian Economic Commission, the United Nations and the World Bank were used. The using of statistical information sources in such quantity was due to the presence of some discrepancies in the data of national statistical services. As an indicator of remoteness, the geographical distance between the capitals of the countries, expressed in the length of the roads, was used.

\section{Results}

According to the nonlinear relationships of the classical gravity model, all indicators were considered in a logarithmic form. The econometric implementation of the basic gravity model was: 


$$
\begin{aligned}
E_{i j, t}= & -1.096+0.6 G D P_{i, t}+0.5 G D P_{j, t}-1.271 R_{i j} \quad R^{2}=0.469 \\
& (0.67) \quad(0.000) \quad(0.000) \quad(0.000)
\end{aligned}
$$

Where (description of variables given before logarithmication) $E_{i j, t}$ - value volume export from country $i$ to country $j$, in thousands of USD; GDP $i, t$ - GDP of country $i$ (exporter), in thousands of USD; $G D P_{j, t}$ - GDP of country $j$ (importer), in thousands of USD; $R_{i j}-$ remoteness (distance) between capitals of countries $\mathrm{i}$ and $\mathrm{j}, \mathrm{km}$. In parentheses, under the coefficients of the equations, the $P$-value of the $t$-statistic of the coefficient estimate is indicated: all coefficients of the exogenous factors are statistically significant at 0.01 significance level, including the distance variable. The coefficient of determination $\mathrm{R}^{2}=0.469$ of the model (2) is also statistically significant $(\mathrm{P}=0.00)$. The model was evaluated with random period effects according to the Breush-Pagan test results.

The modeling results confirm that the regional trade of countries within the framework of the considered dataset obeys the laws underlying the classical gravity model: the size of the economies of trading partners has a significant positive effect on exports, and the geographical (transport) distance between them has a negative effect on exports. According to the obtained elasticity estimates: the positive dependence of export on the size of the economy of the exporting country is more elastic (corresponding elasticity -0.6 и 0.5 ). The value of the coefficient of elasticity by distance is close to a unitary value, the corresponding $95 \%$ confidence interval is $(-1.78 ;-0.76)$.

Since the coefficients of the variables of the base model (2) are statistically significant and have theoretically expected signs, further, we can include in the model a variable characterizing the intensity of globalization processes in terms of trade relations. As such a variable the globalization index KOF was considered [21]. Directly in the study several options of index were examined, but the main interest for inclusion in the model was the KOFTr index, associated with Trade Globalization. Given the specification of the gravity model under consideration, the index of the exporting country was considered as a variable. After the described specification change, the gravitational model took the form:

$$
\begin{gathered}
E_{i j, t}=-12.5+0.84 G D P_{i, t}+0.41 G D P_{j, t}-1.293 R_{i j}+2.456 \text { KOFTr }_{i, t} \quad R^{2}=0.500 \\
(0.001)(0.000) \quad(0.000) \quad(0.000) \quad(0.000)
\end{gathered}
$$

One would expect that the introduction of a globalization variable will decrease the value of elasticity of export to distance, but the value of the coefficient modulo increased insignificantly (it may also indicate a negligible indirect relationship between these variables). At the same time, the assumption of a positive effect of the globalization index on the trade was confirmed.

\section{Discussions}

To test the hypothesis that over time, the value of elasticity to distance should decrease (and, obviously, the influence of globalization - intensify and the value of the corresponding elasticity is increasing), the model (3) was reevaluated at time intervals, resulting from a reduction in the initial time range. Changes in the respective values of the elasticity coefficients are presented in Fig.1.

As can be judged from the distance elasticity graph, we should make our choice in favor of the hypothesis that the influence of distance on the export decreases over time (which, given the specifics of the sample, may indicate the effectiveness of integration processes in EEU). This is indicated by a decrease in the absolute values of the model coefficients, which are an estimate of the coefficient of elasticity of trade to distance $E(R)$. Note that when 
reducing the considered time interval, the estimations of the coefficients for the GDP variables also increased and began to correspond to the values, which can be characterized as unitary elasticities or oscillating with respect to unity.

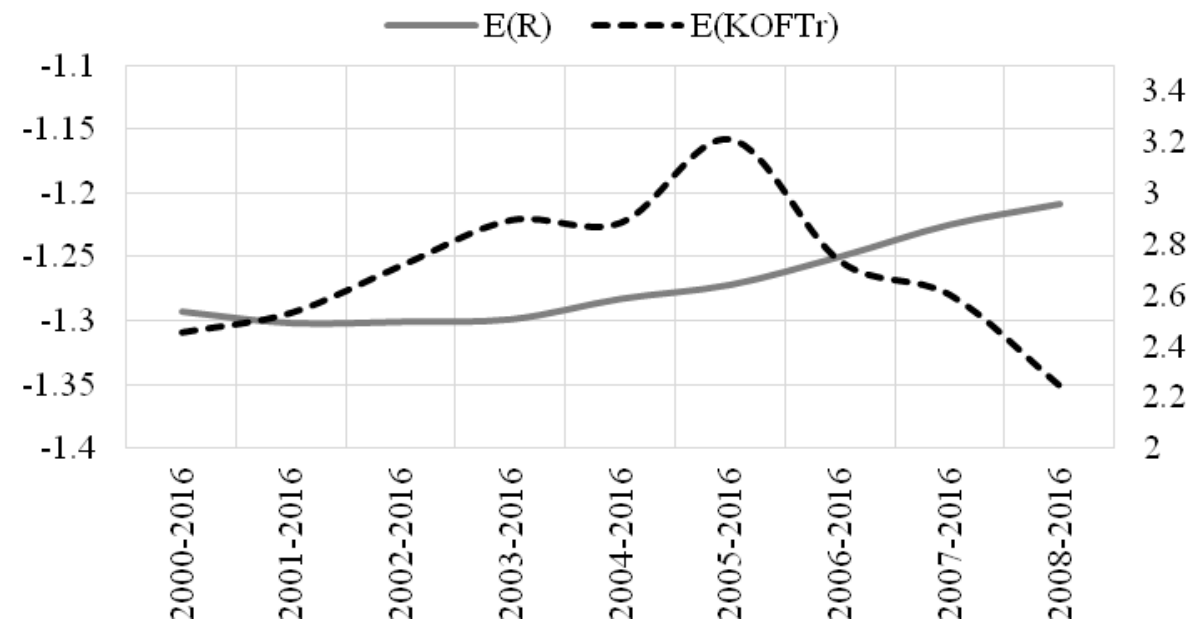

Fig. 1. Changes in elasticity of trade to distance and to level of globalization.

In addition to the conclusion about the positive value of elasticity by the globalization index, the results indicate that the relationship between exports and the index can be described using a curve similar to the inverted "U" shape. This allows to put forward a hypothesis that for low income countries that are at the lower levels of the integration ladder and enter the global commodity markets, the growth rate of foreign trade may initially increase, but over time, as it integrates into the global economic system, it tends to slow down and decline. The fulfillment of the formulated assumption can be explained in particular by the theory of the product life cycle. When including in the integration processes into consideration, the effects of deviation and creation of trade, as well as the effects of expectations (for example, associated with joining an economic or trade union) can be observed.

\section{References}

1. J. Tinbergen, Shaping the World Economy, 5, 27-30 (New York Twentieth Century Fund, 1962)

2. S. J. Evenett, W. Keller, On Theories Explaining the Success of the Gravity Equation. Journal of Political Economy 110, 281-316 (2002)

3. E. Morales, G. Sheu, A. Zahler, Extended Gravity. The Review of Economic Studies, rdz007 (2019)

4. A. C. Disdier, Anne-Célia, K. Head, The Puzzling Persistence of the Distance Effect on Bilateral Trade. Review of Economics and Statistics 90, 37-48 (2008)

5. J. F. Brun, C. Carrere, P. Guillaumont, J. de Melo, Has Distance Died? Evidence from a Panel Gravity Model. World Bank Economic Review 19, 99-119 (2005)

6. J. M. C. Santos Silva, S. Tenreyro, The Log of Gravity. Review of Economics and Statistics 88, 641-658 (2006) 
7. A. J. Knobel, Influence of liberalization of the services sector on service trade and productivity in the industry of Russia and other CIS countries. Applied Econometrics 44, 75-99 (2016)

8. J. Abakumova, O. Primierova, The main aspects of trade integration in the current stage. Regional Economics and Management 3, 136-139 (2015)

9. M. Berthelon, C. Freund, On the Conservation of Distance in International Trade. Journal of International Economics 75, 310-320 (2008)

10. J. F. Brun, P. Guillaumont, J. de Melo, La distance abolie? Criteres et mesures de la mondialisation du commerce exterieur. Globalisation et politiques economiques. Les marges de manoeuvre, 111-138 (1999)

11. E. Leamer, J. Levinsohn, International Trade: The Evidence. Handbook of International Economics 3, 1339-1394 (Elsevier, 1995)

12. E. Jonathan, S. Kortum, Technology, Geography, and Trade. Econometrica 70, 17411779 (2002)

13. D. T. Coe, A. Subramanian, N. T. Tamirisa, R. Bhavnani, The Missing Globalization Puzzle. IMF Working Paper 02/171, (2002)

14. C.M. Buch, J. Kleinert, F. Toubal, The distance puzzle: on the interpretation of the distance coefficient in gravity equations. Economics Letters 83, 293-298 (2004)

15. I. Borchert, Y. V Yotov, Distance, globalization, and international trade. Economics Letters 153, 32-38 (2017)

16. Y. V. Yotov, A simple solution to the distance puzzle in international trade. Economics Letters 117, 794-798 (2012)

17. T. Chaney, The Gravity Equation in International Trade: An Explanation. Journal of Political Economy 126, 150-177 (2018)

18. J. Anderson, E. van Wincoop, Gravity with Gravitas: A Solution to the Border Puzzle. American Economic Review 93, 170-192. (2003)

19. C. Carrere, M. Schiff, On the Geography of Trade. Distance is Alive and Well. Revue Economique 56, 1249-1274 (2005)

20. F. Lin, N. C. S. Sim, Death of distance and the distance puzzle. Economics Letters 116, 225-228 (2012)

21. KOF Globalization Index. [Online]. Available at: http://globalization.kof.ethz.ch (2018) 